\title{
Distance learning and undergraduate Saudi students' agency during the Covid-19 pandemic
}

\author{
Reima AL-JARF ${ }^{1}$
}

To investigate college students' agency during the Covid-19 pandemic, a sample of translation students and instructors was surveyed. It was found that 55\% of the participants were dissatisfied with distance learning $(D L)$, online communication and had difficulty understanding online lectures. Findings also showed absence of goals, low selfefficacy, low student engagement and motivation, and a negative role. The most common concern was exams and passing courses with high grades. Instructors reported that many students were not interested in online learning, in doing assignments, refused to give oral presentations, did not participate in online class discussions, preferred lecture recordings, cheated on exams, overslept and started exams late. Recommendations for increasing translation students' agency in DL are given.

Key-words: student agency, Covid-19 pandemic, distance learning, student engagement, translation instruction, online instruction

\section{Introduction}

Due to the outbreak of the Covid-19 pandemic, there was a sudden shift in schools and universities all over the world from face-to-face teaching and learning to distance teaching and learning. The shift to distance learning (DL) was rapid and abrupt. The students and instructors received no orientation or training with regards to DL. Students and instructors started to work from home using different platforms such as Zoom, Microsoft Teams, Google Classroom, Google Meet, WebEx, in addition to a variety of Learning Management Systems such as Blackboard and Coursera. Instructors and students have had different experiences with $\mathrm{DL}$, some of which are effective and beneficial, and others are frustrating and ineffective.

\footnotetext{
${ }^{1}$ King Saud university, Riyadh, Saudi Arabia, reima.al.jarf@gmail.com
} 
A review of the literature has shown numerous studies that investigated the effect of Covid-19 on distance teaching and learning and the challenges students and instructors faced in DL. For example, the Association of Commonwealth Universities (2020) surveyed digital connectivity and engagement in Commonwealth universities and reported that the most frequently cited challenges were accessibility for students (81\%), staff training and confidence (79\%), connectivity costs (76\%), and student engagement (71\%). $83 \%$ of the respondents from high income-countries had access to broadband, as opposed to $19 \%$ from low-income countries.

In another report, the European Training Foundation (2020) reported responses of 27 educational systems in South Eastern Europe, Turkey, Southern and Eastern Mediterranean, Eastern Europe and Central Asia on how digital DL is delivered and governed, what the level of participation in digital DL is, vocational and work-based learning, teachers competencies in digital DL, what training and support for digital DL is provided, digital DL and inclusion, achievements, challenges in connectivity and devices, challenges for learners, monitoring, isolation and wellbeing, and uncertainty and digital assessment.

In Canada, Doreleyers and Knighton (2020) collected data from 100,000 postsecondary students and reported that $26 \%$ of the students had some of their courses postponed or cancelled due to Covid-19. $7 \%$ reported that they were unable to complete some or all of their courses. The students had concerns about their academic future including concerns about grades, the ability to complete their credential as planned, or that their credential would not be equivalent to those not affected by Covid-19.

In Turkey, teachers criticized the uniform content, teacher-oriented traditional instruction, and the sources and materials utilized in DL. The teachers were not adequately trained in DL. They were unsociable, uncreative and unable to use interactive resources. Resources and materials suitable for DL were inadequate. The students preferred face-to-face live courses, technology-assisted instruction, improved content, communication among students and instructors, and activities that would increase their motivation (Koçoglu and Tekdal 2020).

In Greece, when universities closed, students had strong negative attitudes mixed with temporary joy. When DL classes started, they had positive attitudes, optimism, relief and enthusiasm about $\mathrm{DL}$ as a new mode of learning. Most students did not have any difficulty switching to DL. Participation in online classes increased significantly because more time was available for students and instructors. Students and instructors did not have to commute to campus. Teaching conditions made it easier for students to attend and participate in online classes. The students found online classes interesting. On the other hand, there were some 
negative aspects in DL such as technical problems, lack of communication and cooperation, and limited social contact. Teachers reported that online teaching requires new skills. Both students and instructors pointed out that more content is covered in face-to-face instruction than online instruction. Collaboration between students is greater in face-to-face instruction than DL. Unlike DL, face-to-face instruction develops the dynamics of teamwork. Social interaction and socialization on campus strengthen students' identity as members of a community (Karalis and Raikou 2020).

In Pakistan, $78.6 \%$ of the students felt that contact with their instructor was important for effective learning and indicated that this is present in face-to-face learning but missing in DL. 42.9\% reported lack of interaction with the instructor, long response time and absence of traditional classroom socialization. Lack of oncampus socialization caused difficulties in doing group projects in DL. $50.8 \%$ of the students voted against the possibility of effectively completing entire courses through DL. The researchers concluded that it is necessary for educational institutions to improve their curriculum and design appropriate content for online lectures (Adnan and Anwar 2020).

In Malaysia, Chung, Subramaniam, and Dass (2020) found that college students were generally ready for $\mathrm{DL}$, but they did not want to continue with $\mathrm{DL}$ in the future. Most respondents preferred online learning via pre-recorded lectures uploaded to Google Classroom and YouTube. The biggest challenge for degree students was internet connectivity, but for diploma students was difficulty understanding the course content. The researchers recommended that universities provide further training to enhance instructors' online teaching skills and enable them to deliver lectures more effectively.

In a study with undergraduate students in India and South Korea, Baber (2020) found that classroom interaction, student motivation, course structure, and instructor knowledge positively influenced students' perceived learning outcomes and satisfaction. No significant difference was found between Indian and South Korean students' in their perceptions of learning outcomes and student satisfaction.

In Algeria, EFL students at the department of English Language and Literature at Saida University, preferred face-to-face interaction in the classroom and handouts more than virtual learning. The students were motivated to use both social networks such as Facebook and YouTube and Learning Management Systems such as Moodle as complementary teaching aids (Ghounane 2020)

In Saudi Arabia, Al-Nofaie (2020) taught a morphology class to Saudi English majors via Blackboard during Covid-19. The students reported that they preferred learning via an asynchronous rather than synchronous learning environment due to its flexibility. Barriers to online learning included lack of IT skills and facilities, 
distractions at home, lack of physical interaction, inappropriateness of Blackboard as a venue for taking exams and students' anxiety while taking exams via Blackboard.

Unlike Al-Nofaie's study, Yao, Rao, Jiang, and Xiong (2020) found that live broadcasting with more teacher-student interaction improved students' academic performance more than recorded video teaching for self-study. In the process of online teaching, teachers should not only assume the role of transmitting knowledge but should also provide effective guidance and communication. In another study, Guo (2020) held optional synchronous online sessions in an introductory calculus-based physics class during the original class time, which was attended by half the students. Results showed that the test scores of students who attended the synchronous sessions dropped 3.5\%, whereas test scores of students who did not attend dropped $14.5 \%$. Students who attended synchronous sessions showed a higher gain on the pre and posttest than those who did not (56\% versus 43\%). Students who did not attend the synchronous sessions found the course more difficult and they spent more time studying than those who attended. The researcher recommended that future online classes require mandatory synchronous attendance and participation.

A common challenge in the prior studies reported above is lack of student engagement, communication and interaction with classmates and course instructors in the DL environment during Covid-19. Student engagement plays a significant role in the teaching-learning process. Agency as a component of engagement that considerably contributes to the understanding of how students really engage themselves in learning activities. It enables students to act on their own learning through utilizing the resources and affordances in the learning environment. Student agency is of great importance to success in learning, especially within the DL environment in a world facing Covid-19. Agency can ease the pain of DL and nurturing students' agency has benefits to their engagement, learning, as well as social and emotional well-being. It has a major impact on their self-efficacy, identity, motivation, and metacognition. Positive changes in these four constructs lead to further agentic engagement (Reeve 2012; Waite 2020; Xiao, 2014).

Although agency plays a key-role in the learning process and in the students' academic performance, there is a lack of studies that have investigated the issue of student agency in the transitional DL due to the Covid-19 pandemic, in general, and lack of studies that have investigated how students majoring in translation exercise their agency, in the transitional DL environment at Saudi Universities due to Covid19. For students majoring in translation, it is important that they have agency whether they study face-to-face or online. To bridge this gap, the present study aimed to investigate Saudi college students' agency in DL during the Covid-19 pandemic in the spring semester of 2020. It aimed to explore the following: (i) 
translation students and instructors' views of DL, i.e., advantages, and shortcomings of DL, and whether they found it effective; (ii) how student agency was exercised in DL, i.e. impact of DL on translation students' agency; (iii) students' goal during DL; (iv) kinds of actions taken by the students to achieve their goals; (v) students' beliefs about their self-efficacy in DL; (vi) students' perseverance, and selfdiscipline in DL; (vii) communication, interaction, engagement, offering and receiving feedback in DL; (viii) students and instructors' views of students' engagement in DL; (ix) how teachers encouraged and supported students' agency in DL.

Findings of the present study will shed some light on Saudi students' agency in DL during the Covid-19 pandemic, reasons for low or high agency, engagement, and interaction, the teachers' role in promoting students' agency, and tasks and activities that they might be employed in synchronous DL to promote students' agency. Findings regarding those issues are significant because the primary role of higher education is to develop, promote, and support students' agency to enable them to meet the demands of today's society and working life. Students' agency is also amplified by the integration of modern technologies, solving real-world problems, and learning in a deep and engaging manner.

\section{Theoretical framework}

\subsection{What is student agency?}

There is no consensus among educators on the definition of student agency. In general, agency is the opposite of helplessness. It is a component of personalized learning. It is the capacity to take purposeful initiatives. It gives students voice and choice in how they learn. It involves perseverance and requires skills such as reflection and self-discipline. When students have agency, they set goals, plan, initiate action toward their goals, reflect, and redirect based on feedback from their peers and instructors. They can manage their learning and have an active role in seeking and internalizing new knowledge. They learn through activities that are meaningful and relevant to them, driven and initiated by their interests, and supported by their teachers' guidance. They choose from opportunities provided for them such as projects and assignments. By encouraging students to take the initiative, instructors enhance students' cognitive ability to take control, increase their motivation, and ensure their positive participation in activities. Agency has significant effects on students' academic performance and achievement. It enables them to be confident, adaptive, socially responsible and to find meaning and satisfaction in their lives. It plays a key role in self-regulated learning. It empowers 
them to influence their own path to mastery of learning and to face new challenges (Zeiser, Scholz, and Cirks 2018; Luo, Yang, Xue, and Zuo 2019; Richardson 2019).

\subsection{Components of student agency}

According to Poon (2018), student agency has the following components:

[1] Setting advantageous goals: This incudes awareness of students' current strengths and weaknesses and developing a sense of where they want to go.

[2] Initiating action toward those goals by providing choices or open-ended opportunities for students to select strategies for achieving a goal. It also includes teaching effective learning strategies, such as organization, notetaking, rehearsing; creating learning environments that optimize motivation and engagement; providing students with autonomy; making learning social through group work; and developing a sense of voice, ownership, and selfdetermination.

[3] Reflecting on, revising, and regulating students' progress toward their goals: This includes planning, acting, reflecting, and redirecting. It involves perseverance and grit. It requires reflection, self-discipline, externalizing thinking, and offering, and receiving feedback from instructors and peers.

[4] Internalizing self-efficacy which includes beliefs about self-efficacy, associating their belief in their ability to succeed with their level of effort and their ability to persist when facing challenges. Students with low self-efficacy exhibit learned helplessness, a belief that they "have no power over what is going on around them, and that nothing they do contributes to their success or failure." It includes providing multiple opportunities for the students to develop and showcase their mastery of learning, targeting their zone of proximal development; sharing examples of people who have overcome obstacles; and explicitly attending to the students' physical and emotional wellbeing.

\section{Methodology}

\subsection{Participants}

A total of 174 students and 53 instructors from colleges of languages and translation at 5 Saudi universities (King Saud University, Imam University, Princess Noura University, King Khalid University and King Abdul-Aziz University) 
participated in the study. All the participants are native speakers of Arabic with English as their target language. Student participants are all undergraduate students (freshman, sophomore, junior, and senior). They have different proficiency levels in English and different background knowledge in linguistics, translation, and interpreting. Participating instructors have an M.A. and/or a Ph.D. degree and teach different linguistics, translation, and interpreting courses.

\subsection{Instrument}

To explore students and instructors' impressions of and experience with the sudden transition to $\mathrm{DL}$ at Saudi Universities due to the Covid-19 pandemic, a questionnaire-survey with open-ended questions about transitional DL in the spring 2020 semester was developed and used. The questions asked the participants about the following: their perceptions and views of and experience with DL. i.e., benefits and shortcomings of DL; students' goals during DL; how instructors encouraged and supported students in DL; course material and teaching techniques used in DL; attendance; homework, activities, participation, exams; self-efficacy in DL; interaction and communication between students and instructors; student engagement in $\mathrm{DL}$; offering and receiving feedback from instructors and classmates; students' level of perseverance; whether they prefer DL or face-to-face instruction and why; and whether they prefer to continue using $\mathrm{DL}$ after the pandemic is over and why.

\subsection{Data analysis}

Responses to the questionnaire-surveys were analysed quantitatively and qualitatively. To describe how students exercised their agency in the transitional DL, students and instructors' responses were analysed in terms of the 4 components of agency mentioned in the Theoretical Framework above: (i) Setting advantageous goals; (ii) initiating action toward those goals; (iii) reflecting on, revising and regulating progress toward students' goals; and (iv) internalizing self-efficacy.

For reliability and validity purposes, a sample of students and teachers' responses to the questionnaire-survey were analysed, categorized and quantified by a colleague with a Ph.D. degree in using the same 4 components of student agency and their definitions. Both analyses were compared, and discrepancies were resolved by discussion. The percentage of agreement between the two analysts was $95 \%$. 


\section{Results}

Analysis of students and instructors' responses to the questionnaire-survey showed that $45 \%$ of the participants were satisfied with $D L$ and found it beneficial and effective. Those were instructors and students who are familiar with online teaching and learning, and who were using web-conferencing platforms and Blackboard before the outbreak of Covid-19. Those instructors and students reported that there is no difference between face-to-face and DL in the material covered, using a variety of teaching strategies, online class discussions, homework and group projects, student participation, communicating and interaction. They added that DL saves commuting time and stress in traffic jams. It encourages shy students to interact. Instructors can use extra online material and resources and they do not have to prepare new material every time they teach the same course. Students enjoyed the integration of translation websites and YouTube videos to practice interpreting. They use DL in the convenience of their home. Instructors record lectures and students access them anytime, anywhere and as many times as they wish. Examples of participants' views:

Maha (S): Online classes help me concentrate better and understand better. If there is something that I do not understand or I need to review for exams, I can replay the lecture recording.

Yousef (T): My experience with Microsoft Teams has been excellent. I was very pleased with my students' interaction and participation. The students were committed and responsible.

Lamia (T): The Blackboard tools are wonderful. They help us explore new ways of communication and substitute different aspects of in-class instruction. We should continue to use such platforms after the pandemic is over.

Ahmed (T): Most Saudi universities have a license with Blackboard, but using it is optional. At our university, we have been using Blackboard for 4 years.

On the other hand, analysis of the students and instructors' responses to the questionnaire-survey showed that $55 \%$ of the participants were dissatisfied with DL and found it ineffective and frustrating and preferred face-to-face instruction. Participants with negative experiences reported that DL was ineffective. $71 \%$ of the students had concerns about when and how their courses will be completed, what will happen in the rest of the semester, how courses will continue, and whether 
the course material will be covered. $59 \%$ had difficulty understanding online lectures especially in translation courses where students usually translate a text and discuss their translations with the instructor and classmates. They used the same class material. No online translation material or resources were added. To $58 \%$, DL was a lot of hard work. Courses were back to back without a break. $69 \%$ had problems communicating with their instructors and classmates. It was not possible for them to follow the lecture and chat and respond to it at the same time. Some participants said:

Dalia (S): The instructors just lecture. We just listen. We cannot see them on video.

Lulu (S): I do not understand anything. I do not benefit from online lectures. Just a lot of hard work. I wish they delete part of the course material!

Faiza (T): Students who attend concentrate and understand less in DL. Many do not show up. We cover less material and translate fewer texts than face to face.

The students' most common concern was exams and passing courses with high grades (91\%). They complained about grading and marks. Some requested automatic passing, cancellation, postponement of final exams, to be given projects, reports or research papers instead of exams, or to duplicate marks of the first half of the semester. Since students were not familiar with online exams, they were anxious and wondered if they would do well. Some students declared:

Ali: I suggest that the university cancel exams because they are more threatening to the students' health than the corona virus.

Mohammad: 10 difficult questions to be answered in 10 minutes! Absurd!

Abdul-Aziz: Each instructor gives us the exam date one day before, with a research paper assigned within a short notice, in addition to having to review for several courses. How can we manage?

Layla: I am in a big dilemma. Should I worry about the exam questions that come from Mars, reviewing the whole curriculum to get $20 \%$ of the course mark only, working with slow internet and frozen Blackboard, sparing time for preparing Ramadan dinner, washing dished, and praying. How can I cope!! 
As for translation and interpreting instructors in this group, 57\% reported that students were not interested in online learning, were not enthusiastic, were demotivated and disappointed. The new DL environment did not work for them. $74 \%$ indicated that the online course attendance was not high as in face-to-face classes. The students would appear online, but in reality they were away, because they went online without turning on video camera on and because some instructors recorded their lectures which the students could access later on. No marks were allocated to online class attendance as it is the case in face-to-face classes. Noura commented:

Online classes are boring. I fall asleep during the lecture. If lectures were recorded, I would be able to watch them at my own convenience.

As for online interactivity and engagement, $64 \%$ of the instructors indicated that students refused to give oral presentations online, did not ask intriguing questions, did not participate in online discussions, and did not do assignments. There was little interaction in the online environment. They did not revise nor self-correct their translation, nor each other's translations online, and did not think about translation accuracy and quality carefully. They did not contribute anything meaningful to the discussion of their written translations. They did not post anything of interest to them on Blackboard. They were not willing to consult additional online translation sources. Some student and instructors wrote:

Tahani (S): I do not know how good my translation is, because I do not get feedback from the instructor on my own translation. So why should I do homework?

Nour (S): I feel I am isolated from my classmates and instructor. Assignments are boring and not meaningful to me. We do not do extracurricular and group-based activities related to translation.

Hala (T) Few students are interactive. Online discussions are time consuming as students cannot follow the online corrections of their translations. They do not want to check extra online resources.

Moreover, $57 \%$ of the instructors indicated that DL was new to them and required a new mode of teaching and learning. They did not know how to use the white board, and how to adapt the course material to the new online teaching 
environment. It was difficult for them to lecture and pay attention to the chat and respond to the comments and questions at the same time. $63 \%$ found it difficult to communicate with a large number of students registered in their courses and give feedback for each individual student on their translation of the assigned texts. Some lecturers reported:

Fatima: Preparing for online lectures takes a lot of time and effort especially because I have little experience with the platform tools.

Maryam: Communicating with hundreds of students individually and providing feedback on individual student translations every week is impossible.

Furthermore, $69 \%$ of the instructors indicated that online exams were ineffective. Some students cheated on exams. To avoid students' complaints about grades and negative effects of the lockdown on students' morale, university administrators mandated that instructors be lenient in exams, give easy and straightforward questions, rather than higher-level thinking questions, allow more exam time, and allocate only $20 \%$ instead of $50 \%$ of the total course mark to final exams. The university administration gave the students the option to drop the course, to choose a letter grade or a pass/fail result and whether to have the course mark included in their GPA. As a result, all the students passed their exams and did not feel that they had to work hard. Some instructors declared:

Mona: I have doubts about whether some students took the tests themselves as they their video camera was off during the exam.

Aisha: Some students overslept, logged in late and started their exam late. I had to give them extra time. It is like given the exam over several times not once. I was obliged to do that, as the administration mandated that we make it easy for students. The administration wants all students to pass to avoid complaints.

Finally, $83 \%$ of the participants reported that the internet was slow, they had difficulty logging into the platform. No technical support was available during online classes and the technical support staff did not respond to their needs and solve Blackboard and connection problems quickly. No academic support was provided to help instructors prepare online material, activities, assignments, and 
tests and help them solve online instructional problems. A student and an instructor commented:

Abdullah (S): Universities are building the students' future on false expectations. They ignore technical problems in Blackboard and slow wi fi. I cannot wait to go back to our classroom after the pandemic is over, as we did not have such problems before. We could communicate and solve our problems face-to-face.

Sami $(T)$ : Absence of prior orientation and training and the sudden use of $D L$ without preparation were inevitable. But this is the best option we have at this stage.

\section{Discussion}

Results of the present study show that that $55 \%$ of the students in the present study have low agency. They show absence of goals in the DL environment related to their role as professional translators and interpreters in the future. The students' only goal was to pass exams, not to learn and practice translation and interpreting skills. The students were passive and did not assume an active role in DL. Their engagement and motivation were low. The students exhibited low selfefficacy and "learned helplessness". They believed that they had no power over what is going, i.e., the unprecedented lockdown due to Covid-19, and that nothing they do can lead to success and passing their courses. DL was teacher-centered, not student-centered. Teachers felt helpless as well. They had a passive role and could not motivate the students, especially when the university administration lowered the pass/fail standards to ease the students' anxiety about passing their courses. They did know how to develop students' autonomy and did not make DL social, because the instructors were unfamiliar with active learning/teaching strategies in DL.

Findings of the present study are consistent with findings of other studies in the literature. As in prior studies by Ghounane (2020), Koçoglu and Tekdal (2020), Karalis and Raikou (2020), Adnan and Anwar (2020), Baber (2020), Al-Nofaie (2020), students in the present study preferred face-to-face instruction and interaction rather than virtual learning via Blackboard, Microsoft Teams or Zoom.

As in the study by Doreleyers and Knighton (2020), students in the present study had concerns about their academic future including issues such as: i) grades; 
ii) their ability to complete their courses as planned, or that their credential would not be equivalent to those not affected by the Covid-19 pandemic; and iii) whether they would be able to earn credit for those courses rather than having to re-take the courses and/or exams later on.

Similar to Chung, Subramaniam and Dass' (2020) study, students in the present research had difficulty understanding the content of synchronous online lectures and preferred online learning via pre-recorded lectures. By contrast, findings of this study are inconsistent with findings of a study by Guo (2020) who reported that students who did not attend synchronous sessions found their courses more difficult and spent more time studying the material, whereas students in the present study found the content of synchronous online lectures difficult to understand and follow and preferred asynchronous recorded lectures.

Lack of engagement, interaction and communication were common problems in DL during the Covid-19 pandemic in studies by Baber (2020) in India and South Korea, Adnan and Anwar (2020) in Pakistan, Karalis and Raikou (2020) in Greece, Al-Nofaie (2020) in Saudi Arabia and in the present study as well. In this respect, Wolverton, Guidry Hollier and Lanier (2020) indicated that students' perceptions of computer self-efficacy lead to student engagement and that student engagement influences group satisfaction in online business courses.

Results of the present study concerning the inadequacies of instructors and complaints of the students are similar to results of a study by Koçoglu and Tekdal (2020) who reported that Turkish teachers lacked online teaching competency, were not sociable and not creative, were unable to use interactive resources, and were inadequately trained in $\mathrm{DL}$. The resources and material in $\mathrm{DL}$ were inadequate. The students preferred face-to-face live courses, technology-assisted education, improved content instruction, communication between the educational components, and activities that would increase their motivation.

Contrary to the results of a study by Karalis and Raikou (2020) in Greece which reported that participation in online classes was high, there were attendance and participation problems in the present study and a high rate of students who missed their online classes.

\section{Recommendations}

Findings of the present study revealed low agency in DL during the Covid-19 pandemic on the part of Saudi students majoring in translation. To promote student agency, this study recommends that translation instructors do the following: 
[1] Help students choose their direction, set their own goal as future translators and interpreters, and become aware of their current strengths and weaknesses.

[2] Help students initiate action through voice, choice, free will, and self-initiation. Students can select strategies for meeting their goals. Provide coursecorrection along the path to mastery of translation skills. Create learning environments that optimize motivation and engagement in translation activities. Create a culture of inquiry and creativity. Encourage independent learning (autonomy) by teaching effective learning strategies such as organizing and note-taking.

[3] Provide their students with opportunities to make choices in how they want to share their learning, in the texts they would like to translate, how they want to translate different genres, and how to showcase what they have learnt about translation.

[4] Help the students reflect and redirect by providing them with opportunities for externalizing their thinking while translating, self-reflection, giving and receiving ongoing feedback from adults and peers on specific translation skills, self-assessment, and building critical awareness of translation quality and accuracy.

[5] Help students internalize self-efficacy by associating their belief in their ability to succeed with their level of effort and ability to persist when facing problems and by sharing experiences of people who have overcome difficulties.

[6] Encourage synchronous class lecture attendance by informing students of attendance requirements in distance education courses.

[7] Promote interactivity and engagement and build a sense of community by focusing on student-centered learning activities such as task-based and opinion-sharing tasks. Use a mix of instructor-led and student-led teaching strategies such as collaborative, team-based, and problem-based learning. Connect students' personal interests to the course content, work-related learning and real-world experiences that impact students' translation careers. Use telecollaboration with translation students taking similar courses. Blend cognitive engagement prompts with emotional engagement and motivation. Use interactive student presentations and demonstrations, video-based and text-based discussions, chatting off-topic, and making communication personal (Knight, Barbera and Appel 2017; Vähäsantanen, Paloniemi, Hökkä, and Eteläpelto 2017; Kohn and Hoffstaedter 2017; Blakey and Major 2019; and Lowenthal, Borup, West, and Archambault 2020). 


\section{Conclusion}

Responses to the questionnaire-survey in the present study about DL during the Covid-19 pandemic revealed that 55\% of translation students and instructors were dissatisfied with distance learning (DL). Findings showed absence of goals, low self-efficacy, low student engagement and motivation, and a negative role in DL. To promote students' agency in DL, instructors and students need instructional and technical orientation, as well as training and support with regards to DL. Competent instructors in IT and distance teaching may give short synchronous or asynchronous training workshops to help those who are less competent and answer their queries about online instruction. Instructors may supplement the DL platform with other technologies that facilitate communication with students such as WhatsApp, telegram or Facebook. Assessing students and instructors' change in experiences, expectations, new trends, and lessons learned in DL, eight months after the outbreak of Covid-19, is still open for further investigation by future researchers.

\section{References}

Adnan, Muhammad and Kainat Anwar. 2020. "Online Learning amid the COVID-19 Pandemic: Students' Perspectives". Journal of Pedagogical Sociology and Psychology 2(1): 45-51.

Al-Nofaie, Haifa. 2020. "Saudi University Students' Perceptions towards Virtual Education during COVID-19 Pandemic: A Case Study of Language Learning via Blackboard". Arab World English Journal 11(3): 4-20.

Association of Commonwealth Universities (Martin Hamilton, Lucy Shackleton, and Rosanna Mann). 2020. Higher Education during COVID-19: A Snapshot of Digital Engagement in Commonwealth Universities. ACU Policy Brief. ERIC No. ED607557, available at https://www.acu.ac.uk/media/2344/acu-policybrief-digital-engagement-2020.pdf.

Baber, Hasnan. 2020. "Determinants of Students' Perceived Learning Outcome and Satisfaction in Online Learning during the Pandemic of COVID19". Journal of Education and e-Learning Research 7(3): 285-292.

Blakey, Carla and Claire Major. 2019. "Student Perceptions of Engagement in Online Courses: An Exploratory Study". Online Journal of Distance Learning Administration 22(4). 
Chung, Ellen, Geetha Subramaniam, and Laura Dass. 2020. “Online Learning Readiness among University Students in Malaysia amidst COVID-19". Asian Journal of University Education 16(2): 46-58.

Doreleyers, April and Tamara Knighton. 2020. "COVID-19 Pandemic: Academic Impacts on Postsecondary Students in Canada". ERIC No. ED605390.

Ghounane, Nadia. 2020. "Moodle or Social Networks: What Alternative Refuge Is Appropriate to Algerian EFL Students to Learn during COVID-19 Pandemic". Arab World English Journal 11(3): 21-41.

Guo, Siming. 2020. "Synchronous versus Asynchronous Online Teaching of Physics during the COVID-19 Pandemic". Physics Education 55(6).

Jiang, Anne and Lawrence Zhang. 2019. "Chinese Students' Perceptions of English Learning Affordances and Their Agency in an English-Medium Instruction Classroom Context". Language and Education 33(4): 322-339.

Karalis, Thanassis and Natassa Raikou. 2020. "Teaching at the Times of COVID-19: Inferences and Implications for Higher Education Pedagogy". International J. of Academic Research in Business and Social Sciences 10(5): 479-493.

Knight, Janine and Elena Barberà. 2017. "Learner Agency and Its Effect on Spoken Interaction Time in the Target Language. JALT CALL Journal 13(3): 167-186.

Knight, Janine and Elena Barberà. 2018. "Navigational Acts and Discourse: Fostering Learner Agency in Computer-Assisted Language Learning." Electronic Journal of e-Learning 16(1): 67-76.

Knight, Janine, Elena Barberà, and Christine Appel. 2017. “A Framework for Learner Agency in Online Spoken Interaction Tasks." ReCALL 29(3): 276-293.

Koçoglu, Erol and Danyal Tekdal. 2020. "Analysis of Distance Education Activities Conducted during COVID-19 Pandemic." Educational Research and Reviews 15(9): 536-543.

Kohn, Kurt and Petra Hoffstaedter. 2017. "Learner Agency and Non-Native Speaker Identity in Pedagogical Lingua Franca Conversations: Insights from Intercultural Telecollaboration in Foreign Language Education." Computer Assisted Language Learning 30(5): 351-367.

Lee, Woogul and Johnmarshall Reeve. 2012. "Teachers' estimates of their students' motivation and engagement: Being in synch with students." Educational Psychology 32(6): 727-747.

Lowenthal, Patrick, Jered Borup, Richard West, and Leanna Archambault. 2020. "Thinking beyond Zoom: Using Asynchronous Video to Maintain Connection and Engagement during the COVID-19 Pandemic." Journal of Technology and Teacher Education 28(2): 383-391. 
Luo, Heng, Tingting Yang, Jin Xue, and Mingzhang Zuo. 2019. "Impact of Student Agency on Learning Performance and Learning Experience in a Flipped Classroom." British Journal of Educational Technology 50(2): 819-831.

Martin, Katie. 2020. "5 Ways to Activate Learner Agency in Distance Learning." Retrieved on October 20, 2020 from https://katielmartin. com/2020/08/16/5-ways-to-activate-learner-agency-in-distance-learning/

Poon, Jennifer. 2018. "What do you mean when you say student agency?" Retrieved on October 20, 2020 from https://educationreimagined.org/what-do-you-mean-when-you-say-student-agency/

Reeve, Johnmarshall and Ching-Mei Tseng. 2011. "Agency as a fourth aspect of students' engagement during learning activities." Contemporary Educational Psychology 36(4): 257-267.

Reeve, Johnmarshall and Stephanie Shin. 2020. "How Teachers Can Support Students' Agentic Engagement." Theory Into Practice 59(2): 150-161.

Reeve, Johnmarshall. 2012. "A self-determination theory perspective on student engagement." In Handbook of Research on Student Engagement, ed. by Sandra Christenson, Amy Reschly, and Cathy Wylie, 149-172. Boston: Springer.

Reeve, Johnmarshall. 2013. "How Students Create Motivationally Supportive Learning Environments for Themselves: The Concept of Agentic Engagement." Journal of Educational Psychology 105(3): 579-595.

Richardson, Will. 2019. "Sparking Student Agency with Technology." Educational Leadership 76(5): 12-18.

Vähäsantanen, Katja, Susanna Paloniemi, Päivi Hökkä, and Anneli Eteläpelto. 2017. "Agentic Perspective on Fostering Work-Related Learning." Studies in Continuing Education 39(3): 251-267.

Waite, Chelsea. 2020. "How student agency can ease the pain of remote learning and teaching". Retrieved on October 20, 2020 from https://www.edsurge.com/ news/2020-06-11-how-student-agency-canease-the-pain-of-remote-learning-and-teaching

Wolverton, Colleen, Brandi Guidry Hollier, and Patricia Lanier. 2020. "The Impact of Computer Self Efficacy on Student Engagement and Group Satisfaction in Online Business Courses". Electronic Journal of e-Learning 18(2): 175-188.

Xiao, Junhong. 2014. "Learner Agency in Language Learning: The Story of a Distance Learner of EFL in China." Distance Education 35(1): 4-17.

$\mathrm{Xu}$, Jianwei. 2012. "Learner Contribution to English Language Learning: Chinese Research Students' Agency and Their Transitional Experiences in Australia." Higher Education Research and Development 31(4): 585-597. 
Yao, Jijun, Jialong Rao, Tao Jiang, and Changqian Xiong. 2020. "What Role Should Teachers Play in Online Teaching during the COVID-19 Pandemic? Evidence from China." Science Insights Education Frontiers 5(2): 517-524.

Zeiser, Kristina, Carrie Scholz, and Victoria Cirks. 2018. Maximizing Student Agency: Implementing and Measuring Student-centered Learning Practices. Washington: American Institutes for Research. 